\title{
Age and Growth of the Pleuronectid Flounder Limanda yokohamae in Tokyo Bay, Japan
}

\author{
Gultneh Solomon, ${ }^{* 1}$ Mitsuhiko Sano, ${ }^{* 2}$ Makoto Shimizu, ${ }^{* 2}$ \\ and Yukio Nose*2 \\ (Accepted August 18, 1986)
}

\begin{abstract}
Age and growth of the pleuronectid flounder Limanda yokohamae in Tokyo Bay were studied by otolith reading of 155 fish. Examination of the outer margins of the otoliths showed that the hyaline zone as annulus was formed once a year and that its formation was completed at the end of the spawning season (February to April). Growth of the fish was expressed by the von Bertalanffy's equation as $L t=260.4[1-\exp \{-0.510(t+0.054)\}]$ for males and $L t=363.1[1-$ $\exp \{-0.311(t+0.285)\}]$ for females, where $L t$ is standard length in $\mathrm{mm}$ and $t$ is age in yezrs. It was found that the growth of males and females differs, with the females showing a higher growth than the males at each estimated age. Growth in body weight was also examined. Most of the fish examined were found to be not more than three years old, although the oldest fish were 5 years old for males and 6 years old for females.
\end{abstract}

Limanda yokohamae is distributed in Japan from southern Hokkaido to Oita Prefecture in Kyushu, the Yellow Sea, the Gulf of Po-Hai, and the northern part of the East China Sea. It inhabits sandy-mud bottoms less than $100 \mathrm{~m}$ depth. ${ }^{1}{ }^{\text {) }}$ It is fished mainly by bottom trawl and gillnets and is an important commercial fish in several parts of Japan. ${ }^{2-6)}$ Landings of this species in Tokyo Bay have recently been increasing steadily. At Shiba fish market in Kanagawa Prefecture, for example, the landing was 5 tons in 1970 and increased to about 446 tons in 1985 . On the other hand, the catch of the stone flounder Kareius bicoloratus was much higher up to 1973 than that of $L$. yokohamae, however this situation was reversed after $1973,{ }^{7,8)}$

We have been carrying out studies on the temporal fluctuation of fishery organism populations in relation to environmental changes. ${ }^{7,93} L$. yokohamae is one of the most important target species of small bottom trawl fishery in Tokyo Bay and a comprehensive study of the fisheries biology of this species will be conducted in near future. The age and growth of $L$. yokohamae have been studied in some parts of the country, ${ }^{4}$ but no studies have been conducted in Tokyo Bay. Here, the otoliths of L. yokohamae, which have been collected during the investigation on the distribu- tion pattern of the fishery organisms in this bay, ${ }^{\theta)}$ were utilized to examine the age and growth of this species preliminarily. Although the number of samples is not large enough and the collection period is rather long, some useful information on age determination and growth was obtained and is reported.

\section{Materials and Methods}

Otoliths of L. yokohamae collected from fish samples in Tokyo Bay from 1974 to 1983 by commercial bottom trawling were used for age determination. A total of 161 specimens was examined and 155 of them were readable. The specimens were measured to the nearest $\mathrm{mm}$ of standard length and weighed to the nearest $\mathrm{g}$. The standard lengths were from 85 to $319 \mathrm{~mm}$ and 74 to $346 \mathrm{~mm}$ for male and female fish, respectively.

All otoliths removed from the fish were kept in glass vials. Some of the otoliths, especially the larger ones were ground until the opaque and hyaline zones could be seen clearly. The smaller otoliths did not require grinding. The otoliths were placed in watch glass containing glycerine with black background to facilitate reading. They were examined using Nikon SMZ-10 microscope with reflected light and measured to $0.01 \mathrm{~mm}$ with

* Japan Overseas Cooperation Volunteers, Japan International Cooperation Agency, Hiroo, Shibuya,

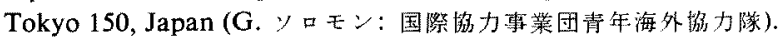

*2 Department of Fisheries, Faculty of Agriculture, University of Tokyo, Yayoi, Bunkyo, Tokyo 113, Japan (佐野光讋, 清水 誠, 能勢幸雄: 東京大学㖘学部水産学科). 


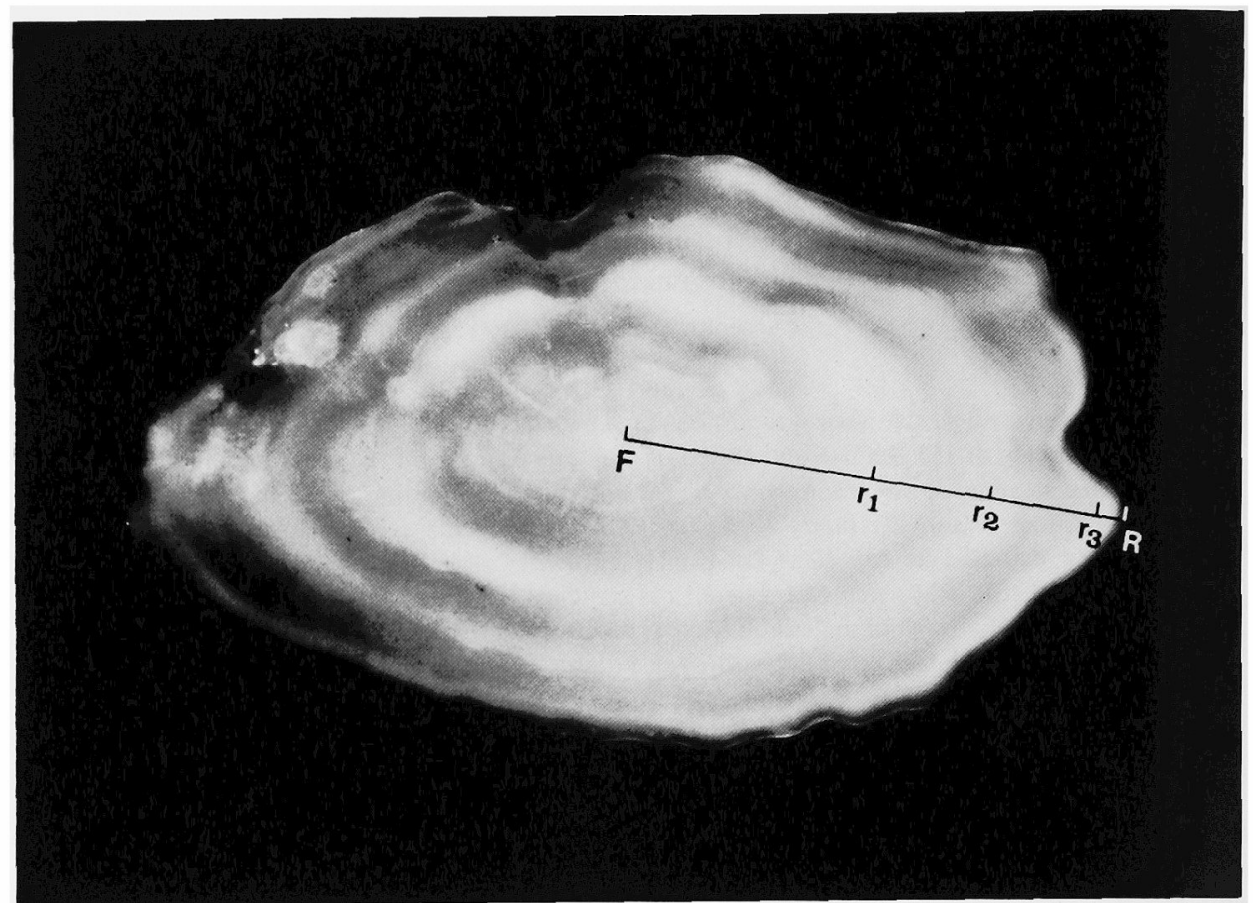

Fig. 1. Otolith of a 3 years old female ( $285 \mathrm{~mm}$ in standard length) of Limanda yokohamae from Tokyo Bay in June, 1980 . $\mathrm{R}$, otolith radius $(3.35 \mathrm{~mm}) ; r_{1}-r_{3}$, annual ring radii $1-3 ; \mathrm{F}$, focus.

the built-in microscope measuring device (K. K. Kougaku). Of each otolith pair, those from the blind side of the fish were found suitable for reading and used for measurement. The otolith radius and the ring radii were measured from the center of the nucleus to the distal margin of the otolith and to the outer margins of the hyaline zones, respectively (Fig. 1).

Monthly changes in percentage occurrence of the otolith with opaque and hyaline margins were examined. This observation was made using 140 otoliths from fish less than 4 years old out of the 155 otoliths used for reading and 23 additional otoliths from fish of unknown sexes.

\section{Results}

\section{Otolith Margin}

Monthly changes in percentage occurrence of the otolith with opaque and hyaline margins are shown in Fig. 2. The opaque zone begins forming from February to April and ends in June. From July to January only the hyaline zone appeared. Therefore, the hyaline zone formation is completed in the period from February to April. This period coincides with the end of the spawning season (December to February) in Tokyo Bay. ${ }^{10,11)}$ These

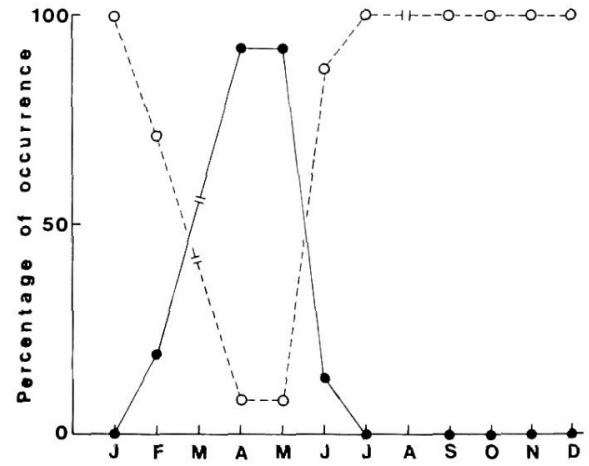

Fig. 2. Monthly changes in percentage occurrence of otolith with opaque (-) and hyaline ( $\bigcirc$--- $)$ margins for Limanda yokohamae from Tokyo Bay. Only fish less than 4 years old were used.

data indicate that the hyaline zone can be used as annulus for age determination.

\section{Relationship between Otolith Radius and Standard Length}

The relationship between otolith radius and standard length is shown in Fig. 3 as a straight line. The equations are as follows: 


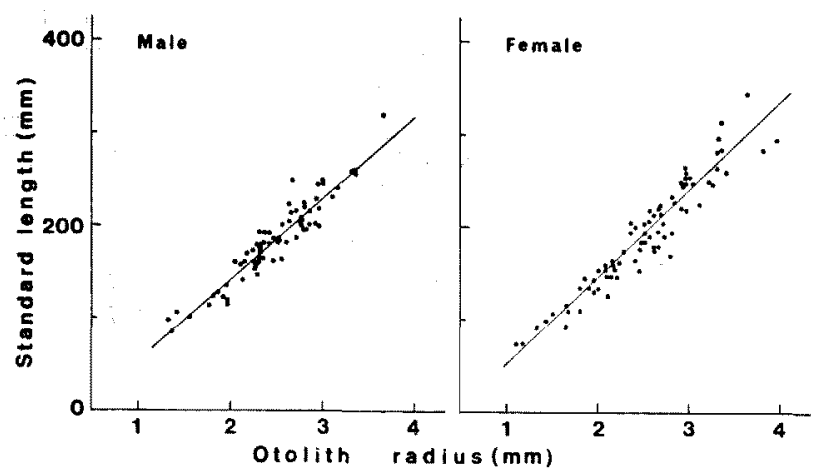

Fig. 3. Relationship between otolith radius and standard length for male and female Limanda yokohamae from Tokyo Bay.

Table 1. Mean otolith ring radii ( $\pm \mathrm{SD})$ at estimated age for male Limanda yokohamae in Tokyo Bay, Japan

\begin{tabular}{|c|c|c|c|c|c|c|}
\hline \multirow{2}{*}{ Estimated age } & \multirow{2}{*}{$\mathbf{N}^{*}$} & \multicolumn{5}{|c|}{ Mean otolith ring radii in $\mathrm{mm}$} \\
\hline & & $r_{1}$ & $r_{2}$ & $r_{3}$ & $r_{4}$ & $r_{5}$ \\
\hline 1 & 37 & $1.67 \pm 0.16$ & & & & \\
\hline 2 & 23 & $1.55 \pm 0.16$ & $2.41 \pm 0.24$ & & & \\
\hline 3 & 2 & 1.73 & 2.50 & 2.90 & $\therefore$ & \\
\hline 4 & 5 & $1.57 \pm 0.17$ & $2.20 \pm 0.14$ & $2.56 \pm 0.12$ & $2.75 \pm 0.12$ & \\
\hline 5 & 2 & 1.58 & 2.28 & 2.68 & 3.03 & 3.19 \\
\hline \multirow{2}{*}{\multicolumn{2}{|c|}{$\begin{array}{c}\text { Weighted mean } \pm \mathrm{SD} \\
\mathrm{N}^{*}\end{array}$}} & $1.63 \pm 0.16$ & $2.37 \pm 0.24$ & $2.66 \pm 0.24$ & $2.83 \pm 0.23$ & 3.19 \\
\hline & & 69 & 32 & 9 & 7 & 2 \\
\hline
\end{tabular}

- N, number of fish examined.

Table 2. Mean otolith ring radii $( \pm \mathrm{SD})$ at estimated age for female Limanda yokohamae in Tokyo Bay, Japan

\begin{tabular}{|c|c|c|c|c|c|c|c|}
\hline \multirow{2}{*}{ Estimated age } & \multirow{2}{*}{$\mathbf{N}^{*}$} & \multicolumn{6}{|c|}{ Mean otolith ring radii in $\mathrm{mm}$} \\
\hline & & $r_{1}$ & $r_{2}$ & $r_{3}$ & $r_{4}$ & $r_{5}$ & $r_{8}$ \\
\hline 1 & 32 & $1.72 \pm 0.19$ & & & & & \\
\hline 2 & 14 & $1.65 \pm 0.12$ & $2.42 \pm 0.20$ & & & & \\
\hline 3 & 10 & $1.72 \pm 0.21$ & $2.43 \pm 0.15$ & $2.93 \pm 0.19$ & & & \\
\hline 4 & 4 & $1.82 \pm 0.09$ & $2.45 \pm 0.19$ & $2.88 \pm 0.18$ & $3.13 \pm 0.25$ & & \\
\hline 5 & 3 & $1.80 \pm 0.28$ & $2.43 \pm 0.28$ & $2.92 \pm 0.28$ & $3.23 \pm 0.35$ & $3.40 \pm 0.36$ & \\
\hline 6 & 1 & 1.45 & 2.25 & 2.90 & 3.40 & 3.65 & 3.75 \\
\hline \multirow{2}{*}{\multicolumn{2}{|c|}{$\begin{array}{l}\text { Weighted mean } \pm S D \\
N^{*}\end{array}$}} & $1.71 \pm 0.18$ & $2.42 \pm 0.18$ & $2.91 \pm 0.18$ & $3.20 \pm 0.27$ & $3.46 \pm 0.32$ & 3.75 \\
\hline & & $\overline{64}$ & 32 & $\overline{18}$ & 8 & 4 & 1 \\
\hline
\end{tabular}

* $\mathrm{N}$, number of fish examined.

Male $\quad L=-33.8+87.88 R \quad(r=0.938)$

Female $\quad L=-43.3+95.19 R \quad(r=0.951)$

where $L$ is standard length in $\mathrm{mm}$ and $R$ is otolith radius in $\mathrm{mm}$. Covariance analysis showed no significant difference in slopes between males and females, but a highly significant difference in adjusted means was found. Therefore, the data were treated separately for each sex.

\section{Age and Growth}

Most of the fish examined were found to be not more than three years old, although the oldest fish were 5 years old for males and 6 years old for females.

The mean radius of each successive otolith ring at each estimated age for males and females is shown in Tables 1 and 2, respectively. From this 
Table 3. Mean back-calculated standard lengths ( $\mathrm{mm})$ at estimated age and those predicted by the von Bertalanffy equation for Limanda yokohamae in Tokyo Bay, Japan

\begin{tabular}{cccccc}
\hline & \multicolumn{2}{c}{ Male } & & \multicolumn{2}{c}{ Female } \\
\cline { 2 - 3 } \cline { 5 - 6 } Estimated age & Back-calculated & $\begin{array}{c}\text { Predicted from } \\
\text { the von } \\
\text { Bertalanffy } \\
\text { growth equation }\end{array}$ & & Back-calculated & $\begin{array}{c}\text { Predicted from } \\
\text { the von } \\
\text { Bertalanffy } \\
\text { growth equation }\end{array}$ \\
\hline 1 & 109.4 & 108.3 & & 119.6 & 119.4 \\
2 & 174.5 & 169.1 & & 187.2 & 184.5 \\
3 & 199.9 & 205.6 & & 233.9 & 232.2 \\
4 & 214.9 & 227.5 & & 261.4 & 267.1 \\
5 & 246.5 & 240.6 & & 286.2 & 292.7 \\
6 & & & 313.6 & 311.5 \\
\hline
\end{tabular}

result it is known that Lee's phenomenon is not present and therefore the weighted mean radius of each ring was calculated and used for backcalculating the fish length. The mean standard length back-calculated from otolith readings at each estimated age is shown in Table 3. The von Bertalanffy's growth equations calculated using the back-calculated length are as follows:

Male $\quad L t=260.4[1-\exp \{-0.510(t+0.054)\}]$

Female $\quad L t=363.1[1-\exp \{-0.311(t+0.285)\}]$

The standard lengths at each estimated age calculated from the above equations are also shown in Table 3. It was found that there is a difference in growth between males and females, where the female fish show a higher growth than the male fish at each age (Table 3, Fig. 4).

\section{Body Weight}

The relationship between the standard length and body weight is shown in Fig. 5. Covariance analysis showed no significant difference between male and female fish in both slopes and adjusted means. Therefore, the data were pooled and the relationship between the standard length $(L, \mathrm{~mm})$ and body weight $(W, \mathrm{~g})$ is estimated as follows:

$$
W=1.37 L^{3.11} \times 10^{-5} \quad(r=0.994)
$$

The von Bertalanffy's growth equations for body weight are as follows:

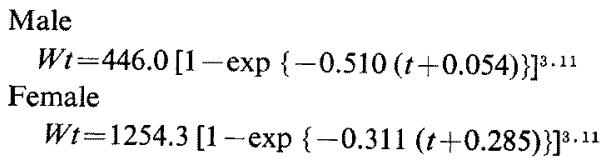

\section{Discussion}

The otolith samples examined could be read clearly without much difficulty, since the margins between the hyaline and opaque zones are clearly defined. Out of a total of 161 samples of $L$.

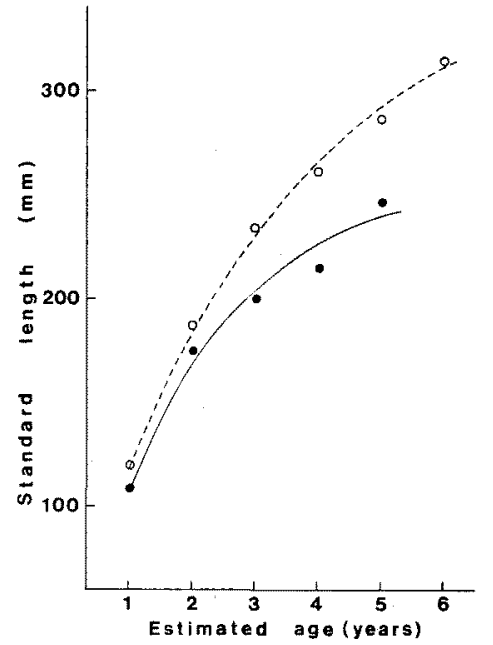

Fig. 4. Von Bertalanffy's growth curve for male (solid line) and female (dashed line) Limanda yokohamae from Tokyo Bay. The data points (๑, male; 0 , female) are the back-calculated standard lengths at estimated age.

yokohamae checked, more than $95 \%$ of them were readable and only 6 specimens were regarded as their ring number to be uncertain for reading or could not be measured with certainty and thus rejected. Most of these rejected specimens belonged to three or more years old fish collected in 1974 and 1977.

The age and growth of the fish were estimated precisely using well known procedures. However, we believe it is important to undertake the validation studies to assess the accuracy of our age determination which we were not able to conduct in the present study.

Comparison of the results from the present study of the fish growth with other studies showed 


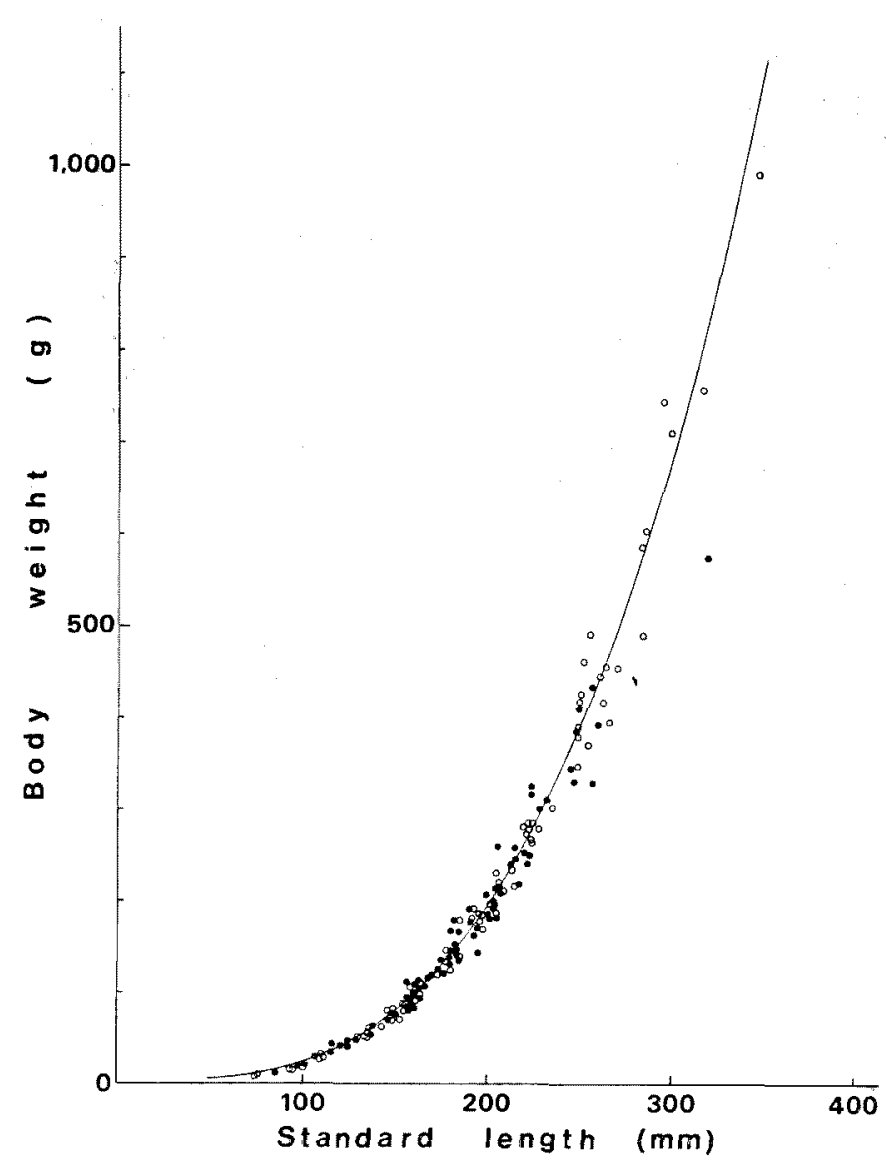

Fig. 5. Relationship between standard length and body weight for Limanda yokohamae from Tokyo Bay. The data for the male $(\bullet)$ and female $(0)$ fish were pooled (see text).

that the fish in Tokyo Bay have a larger $L_{\infty}$ and a larger length at each age for both male and female fish than those in Suo-Nada of Seto Inland Sea. ${ }^{4}$ In Tokyo Bay $L_{\infty}$ was $260.4 \mathrm{~mm}$ and $363.1 \mathrm{~mm}$ for male and female fish, respectively, while in SuoNada it is reported as $240 \mathrm{~mm}$ and $313 \mathrm{~mm}$ for male and female fish, respectively. In Suo-Nada, the oldest age for male and female fish was 6 and 7, respectively, while it was 5 and 6 in Tokyo Bay. We found it difficult to compare our data with that reported from Ise Bay due to the difference in the procedure of the growth estimation. ${ }^{12}$

Although $K$. bicoloratus is known to have a higher growth rate and attains maturity earlier than $L$. yokohamae, ${ }^{3,4,13-15)}$ the recent reverse trend in the fish catch between these two species in Tokyo Bay has been suggested to be the favorable change in the habitat for the latter species as one of the causes. ${ }^{8)}$ Unfortunately, at present the lack of enough biological and environmental information made it difficult to resolve this problem. The present work is a first step to find out how the population changes its age structure and growth in the bay in reaction to either the environmental change or the continuous increase in the fish exploitation. To attain this, it is essential to continue the study of the age and growth of the fish in the bay.

\section{Acknowledgments}

We are very grateful to Dr. Muneharu Tokimura in providing us the otolith specimens and also to the Shiba Fishermen's Union for their help in collecting the fish samples. 


\section{References}

1) K. Sakamoto: in "The Fishes of the Japanese Archipelago" (ed. by H. Masuda, K. Amaoka, C. Araga, T. Uyeno, and T. Yoshino), Tokai Univ. Press, Tokyo, 1984, p. 338. (in Japanese).

2) Y. Nose: in "Productivity of Biocenoses in Coastal Regions of Japan" (ed. by K. Hogetsu, M. Hatanaka, T. Hanaoka, and T. Kawamura), Univ, of Tokyo Press, Tokyo, 1977, pp. 208-212.

3) T. Kawasaki: Nippon Suisan Gakkaishi, 48, 605609 (1982).

4) Y. Masaki, H. Ito, T. Tokai, and Y. Yamaguchi: Nippon Suisan Gakkaishi, 52, 423-433 (1986). (in Japanese).

5) Y. Masaki, H. Ito, Y. Yamaguchi, and T. Tokai: Bull. Nansei Reg. Fish. Res. Lab., 20, 13-37 (1986). (in Japanese).

6) M. Omori: Nippon Suisan Gakkaishi, 40, 11151126 (1974). (in Japanese).

7) Y. Nose: in "Biological Process in the Oceans (Kaiyo no Seibutsu Katei)" (ed. by R. Marumo),
Koseisha-Koseikaku, Tokyo, 1984, pp. 183-186. (in Japanese).

8) M. Shimizu: Aquabiology, 6, 135-139 (1984). (in Japanese).

9) M. Tokimura: On the Structure of the Distribution of Demersal Fish and Shellfish in the Inner Part of Tokyo Bay, Doctoral Thesis, Univ. of Tokyo, 1985, pp. 1-156. (in Japanese).

10) J. Nakagome: Bull. Kanagawa Pref. Fish. Exp. Stn., 1, 91-97 (1980). (in Japanese).

11) A. Sugiura and K. Honda: Fish. Biol. Oceanogr. South-West. Waters Japan, 2, 71-80 (1986). (in Japanese).

12) K. Suzuki: Rep. Fac. Fish., Pref. Univ. Mie, 6, 17-27 (1967).

13) M. Hatanaka, M. Kosaka, and Y. Sato: Tohoku J. Agr. Res., 7, 151-162 (1956).

14) M. Hatanaka, M. Kosaka, and Y. Sato: Tohoku J. Agr. Res., 7, 163-174 (1956).

15) Y. Masaki, H. Ito, T. Tokai, and Y. Yamaguchi: Nippon Suisan Gakkaishi, 52, $435-445$ (1986). (in Japanese). 